Universidade do Estado de Santa Catarina

Centro de Educação Superior do Alto Vale do Itajaí

\title{
PRESENÇA DAS CARACTERÍSTICAS QUALITATIVAS DA INFORMAÇÃO CONTÁBIL NAS PRESTAÇÕES DE CONTAS DOS CANDIDATOS A DEPUTADO FEDERAL PELO DISTRITO FEDERAL NAS ELEIÇÕES DE 2014
}

\author{
Gabriel Dias de Paiva ${ }^{1}$, Eduardo Bona Safe de Matos ${ }^{1}$, Edmilson Soares Campos ${ }^{1}$ \\ ${ }^{1}$ Universidade de Brasília- UnB - Faculdade de Economia \\ e-mail de contato: g.dias.silva@bol.com.br
}

\begin{abstract}
Resumo
A contabilidade objetiva fornecer informações de qualidade para a tomada de decisão dos seus diversos usuários de forma útil, sendo esse um mecanismo para a que haja transparência nas ações, com base nas características qualitativas da representação fiel, relevância, compreensibilidade, comparabilidade, verificabilidade e tempestividade. Neste contexto, o presente estudo busca analisar as prestações de contas dos candidatos a deputado federal pelo Distrito Federal nas eleições de 2014 com relação a essas características para examinar, assim, sua transparência. Para tanto, a pesquisa caracteriza-se como exploratória e descritiva, em que é realizado o uso da descrição de características vislumbradas com a análise documental das prestações digitais entregues ao Tribunal Superior Eleitoral pelos candidatos. Dessa forma, concluiu-se que as características qualitativas são prejudicadas pela falta de informações importantes que podem influenciar na tomada de decisão do usuário, comprometendo assim a transparência das mesmas. Contribui-se para a literatura de accountability e para a melhor análise das prestações por parte da população, sendo esperado um efeito de melhoria da qualidade das prestações de contas a partir dos achados desta pesquisa.
\end{abstract}

Palavras-chave: Prestações de Contas; Eleições 2014; Características Qualitativas da Informação Contábil;Transparência.

\section{PRESENCE OF ACCOUNTING QUALITATIVE CHARECTERISTICS INFORMATION IN CANDIDATES ACCOUNTABILITY BY THE FEDERAL DEPUTY CANDIDATES OF FEDERAL DISTRICT IN 2014 ELECTIONS}

\begin{abstract}
One of the Accounting objectives is to ensure the quality information for decision-making of its various users in a useful way, being this a mechanism for which there is transparency in the actions, based on the qualitative characteristic of faithful representation, relevance, understandability, comparability, timeliness and verifiability. Thus, this study seeks to analyze the accountability of candidates for federal deputy for the Federal District in the 2014 elections with respect to these characteristics to examine its transparency. Thus, it is made a prospectus of elections in Brazil, a review of the Brazilian electoral legislation and literature that are listed definitions and discussions made by scholars of the subject. The method used was exploratory and descriptive, it is done using the description of features envisioned with the documentary analysis of digital services delivered to the Superior Electoral Court by applicants. Thus, it was concluded that the qualitative characteristics are hampered by a lack of important information that can influence the user's decision-making, thereby undermining its transparency.
\end{abstract}


Keywords:the Electoral Campaign Account Services. Qualitative Characteristics of Accounting Information.Transparency.

\section{Introdução}

A primeira eleição datada no Brasil aconteceu em 1532, na então Vila de São Vicente, hoje a cidade de São Paulo, para a escolha do Conselho Municipal e, desde então, o processo eleitoral brasileiro passou por diferentes mudanças, até a mais recente história de redemocratização e a elaboração da Constituição de 1988 (NICOLAU, 2012).

Atualmente, a Justiça Eleitoral, por meio do Tribunal Superior Eleitoral (TSE) e dos Tribunais Regionais Eleitorais, tem como uma de suas atribuições a fiscalização, a cobrança e a auditoria das prestações de contas dos candidatos ao pleito no financiamento de suas campanhas.Como defende Mattos (2014), as campanhas eleitorais nas democracias modernas necessitam de recursos financeiros e materiais para divulgarem seus programas e projetos e, com isso, conquistar votos, devendo, assim, haver um controle sobre as operações.

Para tanto, faz-se necessário o uso da contabilidade como ferramenta na evidenciação e no registro da arrecadação e dos gastos eleitorais, além da produção de informações econômicofinanceiras para controle, no caso do TSE, e transparência, no caso dos partidos políticos e candidatos (SILVA, 2007). Como grande parte do financiamento eleitoral advém do setor privado, deve haver clareza à sociedade quanto a fonte e ao destino dos recursos para que os cidadãos possam entender os interesses e promessas de campanha (SILVA, 2007).

Niyama e Silva (2011) afirmam que a Contabilidade não se limita mais a apenas um instrumento de controle da riqueza patrimonial do proprietário, mas sim a um importante instrumento de prestação de informações para a decisão de diversos usuários.

Com o fim da ditadura militar no Brasil e o advento da Constituição Federal de 1988, a transparência do uso dos recursos públicos passou a ganhar maior atenção. A maior participação popular dentro no processo democrático, de acordo com Silva (2007), tem demonstrado cidadãos cada vez mais ativos na escolha daqueles merecedores de seus votos em busca de uma maior eficiência e objetivando o bem comum.

Em 2014, de acordo com o TSE, foram 22.382 candidatos a cargos eleitorais no Brasil, divididas entre os 32 partidos políticos, que buscavam concorrer a uma vaga para presidente, 27 para governadores, 27 senadores, 513 deputados federais, 1035 deputados estaduais e 24 deputados distritais.

O cumprimento da transparência e a prestação de contas da campanha daqueles que irão gerir o país e representar o povo pelos próximos anos é parte importante no processo de moralização da política nacional. O problema proposto para a realização deste trabalho é o questionamento: As prestações de contas elaboradas pelos candidatos a deputado federal pelo Distrito Federal nas eleições de 2014 são transparentes de acordo com as características qualitativas da informação contábil?

O objetivo deste trabalho, portanto, é demonstrar se as informações divulgadas das prestações de contas dos candidatos a deputado federal das eleições de 2014 são transparentes ao levar em consideração as características qualitativas das informações contábeis.

Com os recentes escândalos na política nacional, observa-se cada vez mais a necessidade de clareza e evidenciação dos recursos utilizados na campanha daqueles que concorreram ao último pleito. A partir disso, o controle social em busca da redução da corrupção por meio da análise da origem e do destino dos recursos usados, defendido por Rezende (2013), em grande parte são oriundos de empresas privadas, faz-se necessário para que não se sobreponham interesses individuais em meio ao que seria melhor para a população.

Segundo Silva (2007), são altas as somas de recursos circulando para a conquista de eleitores e essas quantias requerem a fiscalização para que não haja abusos de poder econômico, sendo que as prestações de contas dos candidatos devem seguir um trâmite legal com base na Lei 
4.737/65 ou Código Eleitoral Brasileiro, Lei 9.504/97 ou Lei das Eleições, e para as eleições de 2014, a Resolução TSE nº 23.406/14.

O processo de prestação deve seguir as Normas Brasileiras de Contabilidade, havendo a obrigatoriedade da participação de um profissional contábil no processo (SILVA, 2007; TSE, 2014). Diante disso, a justificativa para a realização desse trabalho é demonstrar a importância da contabilidade no controle social pela necessidade de clareza e evidenciação dos recursos utilizados nas campanhas eleitorais, com qualidade e transparência nas informações disponibilizadas.

Busca-se evidenciar a participação da contabilidade dentro do processo eleitoral, demonstrando que ela pode ser um instrumento de controle social dos atos públicos, em uma área estudada majoritariamente pelo ramo jurídico.

\section{Referencial teórico}

\subsection{Accountability}

A prestação de contas no âmbito público já estava escrita na Carta Universal dos Direitos Humanos (Carta Universal dos Direitos Humanos de 1789, art. 15, apud CASTRO, 2013, p. 534) quando afirma que: "A sociedade tem o direito de pedir contas a todo agente público pela sua administração".

A partir de 1988, com a Constituinte e a implementação do regime democrático no Brasil, a participação cidadã, após anos de ausência, tem se mostrado cada vez maior (ROCHA, 2011). Com isso, a accountability representa um importante instrumento de controle social, transparência e prestação de contas.

O Estado democrático foi o que possibilitou o processo de accountability, pois com ele passou-se a conceder poder aos governantes por meio da escolha popular e esse deve fornecer esclarecimentos que mostrem que seus atos são para o bem do povo (Rocha, 2011)

Em seu sentido mais amplo, Silva (2007) delimita accountability como prestar contas a sociedade dos recursos usados de forma transparente sobre as ações realizadas pelos gestores, em que haja a figura do poder e a necessidade do controle deste.

Já Castro (2013) acredita que o processo de accountability (como a obrigação de prestar contas) foi possível quando se tornou imprescindível a divulgação e a participação popular, situação reforçada por Silva (2007), ao afirmar sua importância para que haja a identificação do destino dos recursos e se o seu uso trouxe benefícios para a sociedade, fazendo da contabilidade uma das principais ferramentas para evidenciar a transparência dos atos dos gestores.

O estudo da accountability no Brasil ganhou destaque quando Campos (1990) iniciou o debate sobre a existência de um termo equivalente em português, e conclui-se que ainda seriam necessários um controle legal mais eficiente, a cultura de controle social da população e o maior interesse em tornar a accountability mais presente na administração pública pelos órgãos competentes.

Os diversos estudos feitos delimitaram a accountability, para Pinho e Sacramento (2009), como o envolvimento do controle, responsabilidade, transparência, prestação de contas, justificativas quanto aos atos realizados e não realizados, podendo ocasionar premiação ou castigo para os responsáveis.

No processo eleitoral, a criação de regras para autenticar a relação entre os representados e representantes, como defende Abrucio e Loureiro (2004), faz da accountability um elemento importante no processo de sufrágio. Para isso, o quadro 1 demonstra quais suas ferramentas para dar maior credibilidade ao processo eleitoral. 


\begin{tabular}{|c|c|c|}
\hline \multicolumn{3}{|c|}{ ACCOUNTABILITY DEMOCRÁTICA } \\
\hline Formas de Accountability & Instrumentos & Condições \\
\hline Processo Eleitoral & $\begin{array}{c}\text { - Sistema eleitoral e partidário } \\
\text { Debates e formas de disseminação } \\
\text { da informação; } \\
\text { - Regras de Financiamento de } \\
\text { Campanha; } \\
\text { - Justiça eleitoral. }\end{array}$ & $\begin{array}{l}\text { - Direitos políticos básicos de } \\
\text { associação, de votar e ser votado; } \\
\text { - Pluralismo de ideias; } \\
\text { - Imprensa livre e possibilidade de } \\
\text { se obter diversas informações. }\end{array}$ \\
\hline
\end{tabular}

Quadro 1: Ferramentas para credibilidade do processo eleitoral

Fonte: Adaptado de Abrucio e Loureiro (2004)

Dessa forma, é imprescindível que haja mecanismos de fiscalização e participação social com transparência e visibilidade, que são delimitados por Sanchez (2002) como o direito de acessos aos arquivos e documentos mantidos pelas autoridades para comprovação de seus atos; criação de uma cultura de informação na qual seja obrigatória a divulgação de informações que interessam aos cidadãos; uso de mecanismos de publicações; e processos simplificados de acesso à informação.

De acordo com Rocha (2011), para que haja transparência e a real participação da população, é necessário que as informações sejam disponibilizadas com precisão e confiabilidade para que os cidadãos possam criar um quadro sobre a atuação do governo e, com isso, cobrar políticas públicas e prestação de contas.

Em vista disso, a transparência possui como elementos básicos a publicidade, como a ampla divulgação e acesso a informação, a compreensibilidade quanto a boa apresentação e linguagem acessível e a sua utilidade no que diz respeito a confiabilidade e relevância (PLATT NETO ET AL., 2007). Dessa forma, é importante que as prestações de contas sejam disponibilizadas com objetividade, clareza e transparência para que seja útil para o usuário.

\subsection{Papel da Contabilidade nas eleições}

A Contabilidade tem como objetivo a correta apresentação do patrimônio na análise e apreensão das causas de suas mutações, aplicando-se também às entidades governamentais, que são aquelas criadas a partir de legislação federal, estadual, distrital ou municipal com autonomia pública de bens, direitos e obrigações (LIMA, 2011).

Com base na Lei 9.096/95, que normatiza os partidos políticos e seus candidatos, "O partido político, através de seus órgãos nacionais, regionais e municipais, deve manter escrituração contábil, de forma a permitir o conhecimento das origens das receitas e a destinação das receitas".

Os usuários das demonstrações contábeis são aqueles que utilizam-se de dados contábeis para satisfazer algumas das suas diversas necessidades de informação (NIYAMA; SILVA, 2011). No Brasil, cabe ao Governo o papel de divulgar as regras contábeis, sendo ele um dos principais agentes na elaboração das normas que interferem e regulamentam a contabilidade (NIYAMA; SILVA, 2011).

Com base no exposto, fica a cargo do TSE a fiscalização quanto ao cumprimento desses pré-requisitos pelos partidos, inclusive aqueles que tangem às contas eleitorais dos seus candidatos, como a discriminação das receitas e despesas destes e a respectiva documentação comprobatória da entrada e saída de acordo como normatiza a Lei (MATTOS, 2014).

Além disso, o Decreto-Lei 9.295/1946 determina que as escriturações contábeis devem ser realizadas por profissionais habilitados e regulamentados como Contadores e Técnicos em Contabilidade. Obrigatoriedade essa reforçada pela Resolução TSE 26.406/2014, que tornou indispensável a assinatura de um especialista contábil nas prestações de contas dos candidatos nas eleições de 2014, o que de acordo com Mattos (2014) dá legitimidade ao processo de 
contabilização efetuado, sendo uma consequência a maior credibilidade e transparência das informações.

Mattos (2014) ainda defende que a Contabilidade é o pilar de sustentação da prestação de contas eleitoral por evidenciar, com o uso do método das partidas dobradas, toda a origem e o destino dos recursos empregados.

\subsection{Características Qualitativas da Informação Contábil}

A contabilidade é uma ferramenta de controle e mensuração patrimonial de uma entidade que disponibiliza aos seus diversos usuários informações úteis para a tomada de decisão. Tais informações são definidas na Resolução CFC n ${ }^{\circ} 1.374 / 2011$ como útil quando relevantes e representarem de forma fiel aquilo a que se propõem a demonstrar, e úteis e melhoradas se forem comparáveis, verificáveis, tempestivas e compreensíveis (REZENDE, 2013).

No Brasil, o CFC, por meio do Comitê de Pronunciamentos Contábeis (CPC), converte as normas internacionais para aplicabilidade no país. O CPC 00 - Estrutura Conceitual para a Elaboração e Divulgação de Relatório Contábil-Financeiro - relata as características qualitativas das demonstrações contábeis como atributos que dão utilidade a elas para os interessados de forma verdadeira e com equidade. Entre esses atributos, cita-se a relevância e representação fiel como fundamentais e comparabilidade, compreensibilidade, tempestividade e verificabilidade como de melhorias.

A relevância é tida como a interferência das informações na tomada de decisão do usuário com base na análise do impacto de eventos futuros, presentes ou passados ou ainda na confirmação ou correção de avaliações anteriores. Na Resolução CFC 1.128/08 demonstra-se o quanto a confirmação de previsões passadas pode influenciar o usuário, pois com frequência projeções futuras de resultados são realizadas com base em informações do passado. Rezende (2013) exemplifica como a informação confirma ou não expectativas passadas e podem reforçar ou mudar as perspectivas sobre resultados futuros.

A representação fiel é o ato de representar da maneira adequada os eventos que estão evidenciados. Dessa forma, uma demonstração contábil deve mostrar de maneira correta os eventos que impactaram o ativo, o passivo e o patrimônio líquido da entidade (CFC, 2008). Para alcançar um retrato fidedigno, a informação deve ser completa, neutra e livre de erros (CFC, 2011).

A informação completa requer que sejam incluídas todas as informações, descrições e explicações necessárias para a análise e entendimento do usuário. A neutralidade é a não distorção dos dados, em que não houve manipulação para melhorar ou não a informação para influenciar na tomada de decisão (CFC, 2011).

A comparabilidade, conforme o CFC, está baseada em comparar as informações de uma entidade ao longo do tempo para traçar tendências e padrões no patrimônio e resultado, abrangendo também o confronto entre diferentes entidades com base em mensuração e apresentações padronizadas.

Para se fazer valer desse comparativo, Silva (2007) atribui dois aspectos que são a uniformidade e a consistência. A uniformidade é uso dos mesmos métodos de mensuração, classificação e evidenciação de fenômenos iguais de forma semelhantes, porém sem o engessamento de uma padronização, sendo possível o aperfeiçoamento das normas contábeis. Enquanto que consistência é a utilização dos mesmos procedimentos contábeis por uma entidade durante um período de tempo.

A compreensibilidade, uma característica de melhoria, consiste no entendimento das informações por aqueles que farão uso delas, partindo de um pressuposto no qual esse usuário possua um conhecimento mínimo sobre a informação demonstrada (CARVALHO; COLARES, 2014). 
Silva (2007) acredita que tal característica está relacionada com a clareza e objetividade que a informação possui. Elementos de organização espacial, recursos gráficos e até mesmo técnicas de redação devem objetivar a completa compreensão. Com isso, devem-se apresentar informações que respondam as necessidades e sirvam de base para conhecimento dos usuários.

Relacionada com a confiabilidade, a verificabilidade é a constatação se aquilo disponibilizado é a verdade, consistindo na capacidade de assegurar, seja por meio de mensuração ou por documentos comprobatórios, que aquela informação é precisa com o que representa na realidade.

Por fim, a tempestividade, juntamente com o equilíbrio entre custo e benefício, equilíbrio entre as características qualitativas e a visão verdadeira e apropriada, é um dos limitadores da relevância e da confiabilidade das informações, pois, se há demora em sua publicação, é possível que essa não tenha mais relevância por não ser mais a realidade da entidade. Apesar disso, deve existir a ponderação entre a questão temporal de divulgação e no quanto se pode confiar no procedimento utilizado, garantindo sua correta execução.

Dessa forma, a observância das características qualitativas das informações contábeis proporciona qualidade para as informações aos usuários.

\section{Procedimentos metodológicos}

A amostra foi determinada pela análise dos candidatos a deputado federal pelo Distrito Federal DF, por ser onde estão localizados os centros dos poderes Legislativo, Executivo e Judiciário da Federação. Além disso, o centro do poder político do país encontra-se no DF, por abarcar a capital federal.

No total, a amostra é composta por 134 candidaturas entre aptos e não aptos. Contudo, essa foi delimitada a apenas aqueles que enviaram por meio digital suas respectivas prestações de contas a Justiça Eleitoral possibilitando assim a análise, como demonstra a tabela 1. Os 134 candidatos selecionados representam aproximadamente $11 \%$ do total de candidatos a todos os cargos eletivos do Distrito Federal.

Tabela 1: Candidaturas a Deputado Federal no DF

\begin{tabular}{l|c|c}
\hline & Candidaturas & Representatividade \\
\hline Aptos & 125 & $93 \%$ \\
\hline Inaptos & 9 & $7 \%$ \\
\hline Prestações entregues & 116 & $87 \%$ \\
\hline Total & 134 & $100 \%$ \\
\hline
\end{tabular}

Fonte: Elaboração própria

Após a seleção da amostra, a coleta de dados foi feita com o acesso a página virtual do TSE, onde estavam disponibilizadas as prestações de contas virtuais encaminhadas pelos candidatos ou comitês financeiros eleitorais até o dia 03 de abril de 2015. Além de informações quanto à identificação e ao registro dos candidatos, por meio de planilhas eletrônicas, estavam informadas as receitas e despesas.

Em posse desses dados, definiram-se os pontos que deveriam ser verificados, naquilo que estava publicado, em busca das características qualitativas da informação contábil. Com isso, entrou-se em contato com o Fale Conosco do TRE - DF por e-mail sobre o acesso a documentação física das prestações e o relatório de auditoria emitido pela Justiça Eleitoral quanto à credibilidade daquilo que foi informado, sendo negado o acesso por ainda estarem sendo feitas as análises por parte do órgão. Dessa forma, a análise baseou-se nas prestações efetuadas eletronicamente.

As prestações de contas virtuais foram analisadas, primeiramente, quanto àquilo que a legislação eleitoral define como obrigatório para divulgação, à exemplo a identificação das origens das receitas e a descrição das despesas realizadas. A partir disso, com base em Silva 
(2007) realizou-se uma análise da presença das características qualitativas nas prestações de contas dos candidatos a deputado federal do DF.

Silva (2007) utilizou a Resolução CFC no 785/95 para elencar quatro características qualitativas da informação contábil: confiabilidade, compreensibilidade, tempestividade e comparabilidade. No presente estudo, são seis características, representação fiel, relevância, compreensibilidade, comparabilidade, tempestividade e verificabilidade, conforme a Resolução $\mathrm{CFC} \mathrm{n}^{\mathrm{o}} 1.372 / 11$ e o pronunciamento técnico CPC 00.

Como demonstrado no quadro 2, a análise foi feita em busca da completude dos dados informados para que seja cumprida a representação fiel, e quando não, o impacto da falta de informação nas prestações de contas. Com base nisso, a clareza e objetividade do que foi divulgado virtualmente, contudo, a verificabilidade com a documentação que comprove as receitas e despesas não foi possível de realização, pois esta ainda estava sendo julgada pela Justiça Eleitoral durante a elaboração desta pesquisa.

\begin{tabular}{|c|l|}
\hline Característica & \multicolumn{1}{|c|}{ Observações } \\
\hline Representação Fiel & $\begin{array}{l}\text { Identificação do beneficiador; } \\
\text { Número do recibo eleitoral; } \\
\text { Registro da documentação comprobatória da despesa. }\end{array}$ \\
\hline Relevância & $\begin{array}{l}\text { Impacto da falta de informação nas prestações; } \\
\text { Porcentagem de candidatos que informaram o documento comprobatório de } \\
\text { despesas; } \\
\text { Candidatos que divulgaram o recibo eleitoral. }\end{array}$ \\
\hline Compreensibilidade & $\begin{array}{l}\text { Descrição clara e objetiva das despesas; } \\
\text { Descrição clara e objetiva das receitas. }\end{array}$ \\
\hline Comparabilidade & $\begin{array}{l}\text { Comparação entre os demonstrativos de diferentes períodos; } \\
\text { Comparação entre receitas e despesas de diferentes candidatos; } \\
\text { Comparação entre arrecadação, gastos e número de votos; } \\
\text { Comparação entre candidatos, a partir de despesas mais relevantes. }\end{array}$ \\
\hline Verificabilidade & $\begin{array}{l}\text { Confirmação quanto a documentação que comprove as doações e gastos; } \\
\text { Evidência do registro de recibos; } \\
\text { Evidência da documentação da despesa. }\end{array}$ \\
\hline Tempestividade & $\begin{array}{l}\text { Entrega da documentação no prazo definido em Lei; } \\
\text { Data da entrega das prestações parciais; } \\
\text { Entrega das prestações finais. }\end{array}$ \\
\hline
\end{tabular}

Quadro 2: Formas de Análises das Características Qualitativas

Fonte: Elaboração própria

Com base no quadro 2, analisou-se as prestações de contas dos candidatos a partir das planilhas elaboradas. Processadas cada despesa e receita, buscou-se as características qualitativas presentes com relação às formas de análise. Com isso, aqueles registros que possuem os requisitos necessários cumprem as características qualitativas, enquanto que as que estes não fossem identificados estariam deficitárias quanto as características.

\section{Resultados e análises}

A pesquisa compreendeu a análise dos dados das prestações de contas e do processo inerente a cada uma delas, e foi realizada verificando-se, exclusivamente, as informações disponibilizadas na página virtual da Justiça Eleitoral.

Foram arrecadados durante a campanha ao pleito $\mathrm{R} \$ 17.980 .850,16$ e foram gastos $\mathrm{R} \$$ 18.043.123,07, ocorrendo um déficit de $\mathrm{R} \$ 62.272,91$ que, de acordo com a legislação, deve ser assumido pelo partido político ou pelo próprio candidato, estando as dívidas liquidadas até a diplomação do candidato eleito. Contudo, a comprovação do pagamento total dos gastos eleitorais não foi confirmada, pois até a realização desse estudo, o Tribunal Regional Eleitoral do Distrito Federal ainda estava analisando o julgamento das prestações de contas de diversos 
candidatos, mesmo o prazo para a auditoria das prestações devendo ser executado antes da diplomação dos candidatos eleitos.

$\mathrm{O}$ resultado referente à diferença entre a arrecadação e os gastos das campanhas, demonstrado na tabela 2 , pode ser segregado entre aqueles candidatos que obtiveram resultados positivos, em que as receitas foram maiores que as despesas, os que zeraram suas contas com arrecadação igual a dispêndios e aqueles que gastaram mais do que receberam em doação.

Tabela 2: Resultados de Campanhas (em Reais)

\begin{tabular}{l|c|c|c|c|c|c|c|c}
\hline & Superávit & \% & Zerados & \% & Déficit & \% & Total & \% \\
\hline Receitas & $10.096 .932,40$ & $56 \%$ & $6.252 .085,99$ & $35 \%$ & $1.631 .831,77$ & $9 \%$ & $17.980 .850,16$ & $100 \%$ \\
\hline Despesas & $10.042 .729,55$ & $56 \%$ & $6.252 .085,99$ & $35 \%$ & $1.748 .307,53$ & $10 \%$ & $18.043 .123,07$ & $100 \%$ \\
\hline Resultado & $54.202,85$ & & - & & $(116.475,76)$ & & $(62.272,91)$ & \\
\hline Total de Candidatos & 50 & $43 \%$ & 53 & $46 \%$ & 13 & $11 \%$ & 116 & $100 \%$ \\
\hline Fonte: Elaborac̃o Própria
\end{tabular}

Fonte: Elaboração Própria

O número de campanhas que conseguiram recursos excedentes corresponde a $43 \%$ do total, com 50 candidatos, que somados obtiveram $\mathrm{R} \$ 54.202,85$ de resultado superavitário. Quarenta e três candidatos obtiveram saldo nulo, ou seja, $46 \%$, já aqueles que ainda deixaram pendências foram 11\%, 13 proponentes, com obrigações que em conjunto equivalem a $\mathrm{R} \$$ $116.475,76$.

Com o uso da estatística descritiva, resumiram-se as informações das amostras como a média e mediana e as medidas de dispersão que traduzem as variações dentro do estudo como a variância e o desvio padrão da amostra examinada, conforme demonstrado na tabela 3 abaixo:

Tabela 3 - Cálculos Estatísticos (em Reais)

\begin{tabular}{l|c|c|c}
\hline & Receitas & Despesas & Resultado \\
\hline Média & $155.007,33$ & $155.544,16$ & $-536,84$ \\
\hline Mediana & $11.754,13$ & $12.241,69$ & - \\
\hline Desvio-padrão & $308.145,69$ & $308.440,06$ & $6.753,63$ \\
\hline
\end{tabular}

Fonte: Elaboração Própria

A averiguação quantitativa das informações disponibilizadas revelou que a média aritmética, ou seja, o quociente entre a soma de todos os valores observados e o número total de observações (MORAIS, 2005) das receitas dos candidatos foi de $\mathrm{R} \$ 155.007,33$, enquanto que a das despesas foi de $\mathrm{R} \$ 155.544,77$. A mediana, sendo a medida de localização do centro da distribuição de dados, no qual 50\% das informações estão abaixo desse valor e a outra metade acima é de $\mathrm{R} \$ 11.754,13$ para as receitas e $\mathrm{R} \$ 12.241,69$ para as despesas.

Contudo, percebeu-se que o candidato que mais arrecadou foi João Alberto Fraga da Silva, que totalizou R\$ 1.515. 281,72, ao mesmo tempo em que Maria Ivoneide Vasconcelos Soares não teve nenhum recurso recebido. Quanto às despesas João Alberto Fraga da Silva permaneceu como aquele com maiores gastos, que atingiram por completo o que foi arrecadado e Mauricio Alves Gomes, que teve dispêndios de R\$ 95,00.

O desvio padrão evidencia a dispersão dos dados em que quanto maior é, maior a variabilidade da amostra. No exame das receitas, esse ficou em $\mathrm{R} \$ 308.145,69$, e das despesas foi de $\mathrm{R} \$ 308.440,06$. Esses valores demonstram o quanto os dados são heterogêneos e variam de um candidato para outro, o que dificultou a criação de um padrão e a análise quantitativa da pesquisa, priorizando assim o estudo qualitativo. Observa-se, nesse caso, pela heterogeneidade da amostra, que a característica da comparabilidade entre prestações de contas dos diferentes candidatos fica prejudicada.

A origem dos recursos utilizados durante a campanha, em que o montante proveniente de pessoas jurídicas representa a grande maioria das receitas com a soma de $\mathrm{R} \$ 12.512 .975,18$ (70\%) e as doações realizadas por pessoas físicas foram de $\mathrm{R} \$ 5.466 .816,13$ (30\%).

A partir das prestações de contas e de Mattos (2014), que segrega os tipos de gastos em quinze categorias de acordo com suas naturezas evidenciadas, foi realizada a tabela 4. 
Tabela 4: Gastos de acordo com sua Natureza

\begin{tabular}{|c|c|c|c|}
\hline Tipo de Despesas & Natureza & Valor (R\$) & $\%$ \\
\hline Pessoal & $\begin{array}{l}\text { Remuneração ou gratificação de qualquer espécie paga a } \\
\text { quem preste serviço às candidaturas ou comitês eleitorais. }\end{array}$ & $5.694 .235,77$ & $32 \%$ \\
\hline Material impresso & $\begin{array}{l}\text { Confecção de material impresso de qualquer natureza ou } \\
\text { tamanho. }\end{array}$ & $5.020 .053,72$ & $28 \%$ \\
\hline Diversas & Não classificadas nas definições anteriores. & $3.415 .380,33$ & $19 \%$ \\
\hline Transporte & $\begin{array}{c}\text { Despesas com transporte ou deslocamento de candidato e } \\
\text { de pessoal a serviço da candidatura. }\end{array}$ & $1.152 .558,09$ & $6 \%$ \\
\hline $\begin{array}{l}\text { Doação a outras } \\
\text { campanhas }\end{array}$ & Doação para outros candidatos ou comitês financeiros. & $1.083 .640,49$ & $6 \%$ \\
\hline Aluguel & Aluguel de locais para a promoção de atos de campanha. & $492.091,00$ & $3 \%$ \\
\hline $\begin{array}{l}\text { Propaganda de Radio e } \\
\text { TV }\end{array}$ & $\begin{array}{l}\text { Produção de programas de rádio, televisão ou vídeo, } \\
\text { inclusive os destinados a propaganda gratuita. }\end{array}$ & $277.430,00$ & $2 \%$ \\
\hline Propaganda e publicidade & $\begin{array}{l}\text { Propaganda ou publicidade direta e indireta, por qualquer } \\
\text { meio de divulgação destinada a conquista de votos. }\end{array}$ & $145.018,69$ & $1 \%$ \\
\hline Correspondência & Correspondência e serviços postais & $93.783,98$ & $1 \%$ \\
\hline $\begin{array}{l}\text { Instalação, } \\
\text { funcionamento e } \\
\text { organização de Comitês }\end{array}$ & $\begin{array}{l}\text { Despesas de instalação, organização, e funcionamento de } \\
\text { comitês e serviços necessários às eleições. }\end{array}$ & $246.514,29$ & $1 \%$ \\
\hline Comícios ou eventos & $\begin{array}{l}\text { Realização de comícios ou eventos destinados a promoção } \\
\text { da candidatura. }\end{array}$ & $143.372,30$ & $1 \%$ \\
\hline Páginas virtuais & Custos com a criação e inclusão de paginas na internet. & $173.041,62$ & $1 \%$ \\
\hline Carro de som & $\begin{array}{c}\text { Montagem e operação de carro de som, de propaganda e } \\
\text { assemelhados. }\end{array}$ & $69.996,00$ & $0 \%$ \\
\hline Multas & $\begin{array}{l}\text { Multas aplicadas, até as eleições, aos partidos, candidatos } \\
\text { ou comitês financeiros por infração no disposto na } \\
\text { legislação eleitoral. }\end{array}$ & $3.556,79$ & $0 \%$ \\
\hline Jingles e slogans & $\begin{array}{l}\text { Produção de jingles, vinhetas, slogans para a propaganda } \\
\text { eleitoral. }\end{array}$ & $32.450,00$ & $0 \%$ \\
\hline \multicolumn{2}{|r|}{ TOTAL } & 18.043.123,07 & $100 \%$ \\
\hline
\end{tabular}

Fonte: Elaboração Própria

A Tabela 4 demonstra como foram empregados os recursos arrecadados durante as eleições de 2014 e suas proporções no total de despesas. A classificação de Mattos (2014) se diferencia do plano de contas elaboradora pelo TSE por ser mais sintética na especificidade das despesas, enquanto que o segundo possui maiores opções para classificação. Há de se dar destaque as baixas de estimáveis em dinheiro segmentadas em contas próprias pelo TSE e não classificadas por Mattos (2014) de forma específica, dessa forma, registradas em diversas.

Na classificação dada por Mattos (2014), a principal despesa é a com pessoal, enquanto que no plano de contas do TSE é com publicidade. Isso ocorre porque Mattos (2014) agrega todas as despesas com mão de obra, como a de pessoal, serviço de terceiros e militância, ao mesmo tempo em que o plano de contas do TSE segrega essas três despesas em diferentes contas.

No plano de contas do TSE, a despesa mais representativa é aquela com publicidade por materiais impressos, representando $23,19 \%$ de tudo que foi gasto em campanha. Esse tipo de dispêndio é o segundo mais relevante para Mattos (2014), englobando as despesas com publicidade impressa e aquela feita em placas, estandartes e faixas. Os itens definidos como baixa de recursos estimáveis em dinheiro ocupam o terceiro lugar, porém não constam nas especificações dadas por Mattos (2014), estando assim classificadas como diversas.

\subsection{Representação fiel}


A representação fiel foi analisada com base nas informações enviadas pelos candidatos à Justiça Eleitoral em sua plenitude quanto aquilo que a legislação normatiza como sendo de divulgação obrigatória.

No que tange às receitas, em todas as doações deve constar a identificação do beneficiador com seu nome e número do CPF ou CNPJ. No caso de um repasse de doação, é necessário o reconhecimento do doador original. Considerando-se confiáveis e verídicas as informações encaminhadas ao TSE e divulgadas pela internet, buscaram-se essas qualidades com relações aos dados registrados em sua total publicação.

O exame das 116 prestações de contas revelou que apenas o candidato Raphael Sebba Daher Fleury Curado obteve recursos de origem não identificada no valor de R \$70,00, o que, de acordo com a Lei, não pode ser utilizado na campanha, devendo ir para o Tesouro Nacional. O reconhecimento das receitas oriundas de forma secundária, ou seja, aquelas que foram repassadas às campanhas de forma indireta, seja por meio dos diretórios partidários ou de outras campanhas, totalizaram $\mathrm{R} \$ 5.734 .252,41$, cerca de $32 \%$ do total auferido de recursos em que estavam identificados o doador original.

Por meio do sistema de prestação de contas eleitoral é possível a emissão dos recibos eleitorais numerados que devem ser emitidos aos doadores para maior controle e transparência do processo, entretanto, foram identificados recebimentos sem a identificação do recibo, totalizando $\mathrm{R} \$ 16.224,20$ (0,09\% das receitas).

O recibo deve ser emitido para todas e qualquer arrecadação para a campanha eleitoral, sendo esse financeiro ou estimável em dinheiro para que haja sua legitimação. Com isso, de um total de 2.845 receitas recebidas em doação, sete $(0,25 \%)$ não continham o registro dos recibos eleitorais A não emissão pode comprometer o julgamento da fidedignidade de tais prestações.

Os gastos eleitorais devem, conforme Mattos (2014), estar respaldados por documentação fiscal, podendo esta ser notas fiscais ou recibos identificados com o CNPJ do candidato ou comitê, o tipo de gasto, o valor e o fornecedor do serviço ou mercadoria. O gráfico 3 demonstra o percentual de despesas em que foram registrados o número das notas fiscais, cupons ou recibos.

Aproximadamente $25 \%$ - ou $\mathrm{R} \$ 4.287 .637,54$ - das despesas declaradas não possuem o registro da documentação que as comprova nos arquivos de prestação de contas enviados virtualmente ao TSE, estando esse montante sem confirmação quanto a sua real utilização. Dessa forma, de um total de 9.322 despesas divulgadas pelos candidatos, cerca de $1.132(12,14 \%)$ não possuíam descrição quanto ao documento comprobatório nas prestações de contas.

\subsection{Relevância}

A falta do número do recibo eleitoral para doação se deu numa pequena porcentagem das prestações, cerca de $0,09 \%$, o que se mostrou imaterial dentro da amostra estudada. No que se refere às despesas, $\mathrm{R} \$ 4.287 .637,54$ de gastos não foram identificados quanto ao número dos recibos, cupons ou notas fiscais emitidas. $\mathrm{O}$ valor das despesas sem a descrição de documentos comprobatórios (equivalente a $25 \%$ do que foi gasto durante as campanhas) é tido como material e relevante quanto a transparência dos dispêndios realizados.

Em uma maior análise, a tabela 5 demonstra o percentual de gastos não evidenciados pelos candidatos.

Tabela 5: Porcentagem de Identificação de Documentação das Despesas Efetuadas

\begin{tabular}{l|c|c}
\hline \multicolumn{1}{c|}{ Documentação } & $\mathbf{N}^{\circ}$ Candidatos & Percentual dos candidatos \\
\hline $100 \%$ preenchida & 18 & $16 \%$ \\
\hline $99 \%$ a75\% preenchida & 17 & $15 \%$ \\
\hline $74 \%$ a 50\% preenchida & 16 & $14 \%$ \\
\hline $49 \%$ a 25\% preenchida & 19 & $16 \%$ \\
\hline $24 \%$ a 1\% preenchida & 35 & $30 \%$ \\
\hline $0 \%$ preenchida & 11 & $9 \%$ \\
\hline
\end{tabular}


Fonte: Elaboração Própria

Centro de Educação Superior do Alto Vale do Itajaí

Dessa forma, como demonstrado na tabela 5, observa-se o percentual de despesas nas quais os candidatos registraram documentações pertinentes em suas prestações de contas. Nota-se que $46 \%$ das candidaturas que entregaram suas prestações de contas ao TSE continham descritos em suas despesas entre $49 \%$ e $1 \%$ dos números das notas fiscais, cupons ou recibos de seus gastos eleitorais. Apenas 18 prestações de contas (16\%) informaram completamente documentos que comprovam suas despesas, enquanto que 11 prestações (9\%) não identificaram nenhuma despesa.

\subsection{Compreensibilidade}

Baseada na clareza com que as informações prestadas estão para o usuário, a compreensibilidade está presente na completude dos dados dispostos e na transparência dos mesmos. Falta de informações, ou obscuridade quanto à descrição podem impedir uma total compreensão das prestações de contas pelos usuários externos, especialmente, o eleitor. Com base nisso, foram analisados os recursos arrecadados e sua aplicação.

Todas as arrecadações de recursos feitas pelos candidatos, mesmo que de recursos próprios, devidamente identificados foram utilizadas para o estudo, em conjunto com gastos efetuados e descritos na lista de receitas e despesas apresentadas pelo TSE. Quando essas não estiverem abrangidas pode-se classificá-las como diversas a especificar, desde que, seja detalhada suficientemente sua origem e destino.

No que diz respeito às despesas, a classificação destas como diversas a especificar, não delimitando a que se tratavam, e equivalendo a 1,28\% da soma dos gastos mostrou-se pouco impactante para o estudo. Quanto às receitas, a tabela 6 traz a análise quanto a clareza da descrição da origem e arrecadação dos recursos.

Tabela 6: Descrição do Tipo de Arrecadação para Campanha Eleitoral

\begin{tabular}{l|c|c}
\hline \multicolumn{1}{c}{ Descrição } & Valor (R\$) & Percentual \\
\hline Transferência eletrônica & $7.417 .238,50$ & $41,25 \%$ \\
\hline Cheque & $5.211 .023,81$ & $28,98 \%$ \\
\hline Estimado em dinheiro & $3.228 .177,05$ & $17,95 \%$ \\
\hline Depósito em espécie & $2.057 .872,81$ & $11,44 \%$ \\
\hline Outros títulos de crédito & $33.301,14$ & $0,19 \%$ \\
\hline Em espécie & $26.178,00$ & $0,15 \%$ \\
\hline Boleto de cobrança & $6.000,00$ & $0,03 \%$ \\
\hline Não informado & 70,00 & $0,00 \%$ \\
\hline Total Geral & $\mathbf{1 7 . 9 8 0 . 8 5 0 , 1 6}$ & $\mathbf{1 0 0 , 0 0 \%}$ \\
\hline
\end{tabular}

Fonte: Elaboração Própria

A proporção de $17,95 \%$ das receitas equivalentes a valores estimadas em dinheiro, evidenciada na tabela 6, não são especificados de forma clara. Esse tipo de receita é composta, segundo Mattos (2014), como bens ou serviços produtos do trabalho, da atividade econômica, ou de posse patrimonial do doador. Para que haja clareza, tais receitas devem ser descritas com o valor unitário, quantidade e valor de mercado, dados esses não encontrados nas prestações divulgadas.

\subsection{Comparabilidade}

A comparabilidade quanto ao confronto entre diferentes períodos traçando padrões e tendências não se tornou possível por não haver períodos anteriores disponíveis para montar uma serie histórica que possibilite uma inferência das informações comparativas, já que esse processo está ligado a um evento único, uma eleição específica (SILVA, 2007). Contudo, as prestações de 
contas devem seguir preceitos legais e são registradas pelo plano de contas disponibilizado pelo TSE, o que viabiliza a comparação entre candidatos.

Em vista, tem-se a observação da comparação e existência de relação entre os candidatos com maiores números de votos, como traz a tabela 7 , com aqueles que obtiveram mais doações e realizaram mais gastos, já que, o principal objetivo das campanhas é a conquista de votos.

Tabela 7: Candidatos Mais Votados para Deputado Federal no DF nas Eleições de 2014

\begin{tabular}{c|l|c|c}
\hline Colocação & \multicolumn{1}{|c|}{ Candidato } & $\mathbf{N}^{\mathbf{0}}$ votos & $\%$ \\
\hline 1 & João Alberto Fraga Silva & 155.056 & $10,66 \%$ \\
\hline 2 & Rogerio Schumann Rosso & 93.653 & $6,44 \%$ \\
\hline 3 & Érika Jucá Kokay & 92.558 & $6,37 \%$ \\
\hline 4 & Ronaldo Fonseca De Souza & 84.583 & $5,82 \%$ \\
\hline 5 & RôneyTâniosNemer & 82.594 & $5,68 \%$ \\
\hline 6 & Alírio de Oliveira Neto & 78.945 & $5,43 \%$ \\
\hline 7 & Izalci Lucas Ferreira & 71.937 & $4,95 \%$ \\
\hline 8 & Vitor Paulo Araújo dos Santos & 71.381 & $4,91 \%$ \\
\hline 9 & Eliana Maria Passos Pedrosa & 55.340 & $3,81 \%$ \\
\hline 10 & Roberto Policarpo Fagundes & 48.037 & $3,30 \%$ \\
\hline & SOMA & 834.084 & $57 \%$ \\
\hline
\end{tabular}

Fonte: TSE

Percebe-se, na Tabela 7, que o candidato que mais arrecadou e gastou recursos, João Alberto Fraga, foi aquele que mais recebeu votos. Além disso, Alírio Neto, Izalci e Eliana Pedroso que foram respectivamente, segundo, terceiro e quarto colocados em recursos eleitorais de campanha estão classificados entre os dez mais votados nas eleições de 2014. Apenas Rafael de Aguiar, o quinto entre os que movimentaram mais recursos eleitorais, não ficou entre os dez, estando na $17^{\circ}$ posição.

\subsection{Verificabilidade}

A verificabilidade não foi possível de execução devido a não disponibilidade dos documentos referentes as prestações de contas. Os relatórios de auditoria que confirmariam a fidedignidade das informações também ainda não estão disponibilizados devido ao TRE ainda estar realizando o julgamento das prestações.

No entanto, baseado nos dados informados por meio eletrônico fez-se valer da veracidade das informações contidas nas prestações de contas virtuais dos candidatos, partindo do pressuposto de que aquilo, efetivamente, condiz com a realidade.

A identificação do doador e a emissão dos recibos eleitoral são imprescindíveis para o cumprimento dessa característica qualitativa da informação contábil e dar-lhe confiabilidade. Dessa forma, conforme anteriormente demonstrado, a proporção de doações sem identificação e número do recibo existe, mas em poucos casos.

Apesar disso, as receitas descritas como estimadas em dinheiro não trazem a descrição necessária para sua identificação, representando aproximadamente $18 \%$ dos recursos arrecadados, fazendo com que haja uma perda de credibilidade quanto aquilo que está sendo informado.

A falta de registro da nota fiscal, cupom ou recibo observadas em cerca de $25 \%$ das despesas faz com que não exista a comprovação da genuinidade desses gastos, havendo uma ressalva por se tratar de um item de valor representativo.

\subsection{Tempestividade}

Relacionada com o fato de a informação chegar a tempo hábil para o usuário para que ele a use na tomada de decisão (SILVA, 2007), a tempestividade foi observada nas 116 prestações estudadas, por meio da observação de suas datas de entrega. O prazo legal para a entrega é de 30 dias após a realização das eleições. Dessa forma, como as eleições foram realizadas no dia 05 de 
outubro de 2014, foi considerado como tempestiva as prestações entregues até 04 de novembro de 2014.

Porém, pode-se observar que com o prazo estipulado por lei é pouco tempestivo para o usuário eleitor das informações prestadas, já que essas só são divulgadas após a realização das eleições, não estando à disposição para a tomada de decisão. Com isso, durante o pleito de 2014 foi normatizado que os candidatos fariam prestações de contas parciais de suas campanhas e essas seriam divulgadas antes do dia da votação.

Como defende Mattos (2014), a adoção da prestação de contas parcial é um importante mecanismo para a transparência do processo de financiamento eleitoral, sendo esta obrigatória para os candidatos e seus comitês e enviada nos dias 28 de julho a 02 de agosto de 2014 e 28 de agosto a 02 de setembro de 2014. A tabela 13 evidencia a entrega dessas prestações pelos candidatos ao pleito de 2014.

As prestações de contas parciais devem conter a discriminação dos recursos recebidos e dos gastos realizados, com o detalhamento dos doadores e fornecedores, e estas devem conter a efetiva movimentação financeiro-econômica ocorrida até a sua data, podendo ser utilizadas durante o julgamento das prestações finais. Entretanto, das prestações parciais entregues, a tabela 8 demonstra aquelas que foram enviadas fora do prazo estipulado por lei.

Tabela 8: Entrega das Prestações de Contas Parciais

\begin{tabular}{l|c|c|c|c|c|c}
\hline & Dentro do prazo & $\mathbf{\%}$ & Fora do prazo & \% & Total & \% \\
\hline $1^{\mathbf{0}}$ parcial & 29 & $50 \%$ & 29 & $50 \%$ & 58 & $100 \%$ \\
\hline $2^{\mathbf{0}}$ parcial & 78 & $92 \%$ & 7 & $8 \%$ & 85 & $100 \%$ \\
\hline
\end{tabular}

Fonte: Elaboração Própria

Apesar de estar demonstrado na tabela 8 que nem todas as prestações parciais foram entregues na data limite prevista em lei, não há uma sanção para a não entrega das prestações parciais, apenas que sua ausência é tida como uma omissão da informação, que pode vir a repercutir na regularidade das contas finais. Mas a falta da publicação destas faz com que não haja a tempestividade ideal para o usuário, no caso, o eleitor. Dos oitos candidatos eleitos em 2014, três não enviaram no prazo a primeira parcial de prestação de contas, e um a segunda.

Mesmo sendo uma obrigação legal a entrega das prestações de contas, esta somente foi cumprida por 116 das 134 candidaturas a deputado federal no DF, sendo que parte destas (51\%) foi entregue fora do prazo estipulado, o que compromete a utilidade da informação. Silva (2007) defende que o não cumprimento do prazo de entrega pode prejudicar o julgamento das contas pela Justiça Eleitoral, pois o prazo para avaliação fica mais limitado. Além disso, não há uma penalidade legal quanto ao não cumprimento do limite de 30 dias corridos.

Dessa forma, a tempestividade ainda se viu cumprida por $49 \%$ das prestações entregues contra 51\% entregues após o dia 04 de novembro de 2014, o que limita o tempo de avaliação desta e compromete sua utilidade. Observou-se que os candidatos eleitos cumpriram a entrega das prestações de contas, mas nenhum em tempo hábil, variando de dez a vinte quatro dias de atraso. Há de se enfatizar que quando se trata do eleitor, a divulgação após o pleito, faz com que haja uma intempestividade quanto ao seu uso.

\section{Considerações finais}

O estudo executado com as prestações de contas das campanhas eleitorais de 2014 dos candidatos a deputado federal pelo DF possibilitou o exame da transparência das informações divulgadas com base na observância das características qualitativas da informação contábeis de representação fiel, relevância, comparabilidade, compreensibilidade, veracidade e tempestividade nelas contidas. Além disso, foi feita a análise descritiva das prestações de contas, em que se notou o valor total arrecadado e gasto, origem dos recursos, despesas mais relevantes e cálculos estatísticos. 
Percebeu-se que a maioria dos recursos recebidos durante as campanhas tem como origem doações de pessoas jurídicas, o que pode ocasionar um jogo de interesse quanto às propostas votadas pelos deputados, em detrimento do que seria melhor para a população em geral. As despesas mais representativas são aquelas identificadas como de publicidade e pessoal por darem maior visibilidade aos candidatos na hora de angariar votos.

Com base nas prestações de contas finais, $43 \%$ dos candidatos obtiveram superávit de $\mathrm{R} \$$ $54.202,85$ (ou seja, arrecadações superiores aos gastos), enquanto que $11 \%$ foram deficitários em $\mathrm{R} \$ 116.475,76$ (gastos superiores às arrecadações declaradas). O restante dos candidatos obteve resultados nulos. Nesse sentido, observa-se que, no total, o confronto entre todas as receitas e despesas revelou um déficit eleitoral total de $\mathrm{R} \$ 62.272,91$, ou seja, foram realizados gastos superiores às receitas declaradas.

A legislação eleitoral brasileira normatiza como deve ser feita a prestação de conta dos candidatos a cargos eleitorais objetivando maior transparência, porém das 134 candidaturas aptas ou não, apenas 116 entregaram suas prestações de contas. Dessa forma, constatou-se a presença do doador e a emissão de recibo eleitoral na maioria das receitas, ao mesmo tempo em que o registro de notas fiscais, cupons ou recibos emitidos referentes as despesas não foram evidenciados em $12 \%$ das divulgações.

Com base nisso, pode-se constatar o cumprimento da representação fiel das receitas, com base no baixo índice de receitas sem recibos, enquanto que apenas uma doação não identificou o beneficiador. Contudo, as despesas sem documento comprobatório representaram $24 \%$ do total arrecado, concluindo que é alto o índice de dispêndios que podem não representar de forma fiel a realidade.

A partir disso, a relevância, por meio da materialidade, da falta de informações nas receitas mostrou-se baixa, enquanto que para as despesas é material por se tratar de uma quantia considerável e que pode influenciar na tomada de decisão pelo usuário. Em conjunto, no que tange a verificabilidade baseada na descrição destas informações também há comprometimento, além de essa não ter sido comprovada por meio da documentação pertinente.

A compreensão das informações divulgadas pode ser influenciada pela falta de clareza de $18 \%$ das receitas das campanhas, por essas serem classificadas como estimáveis em recursos financeiros, não sendo precisa quanto ao tipo de recurso, quantidade e preço para torná-la transparente para aquele que faz uso dessas informações. Em contraponto, têm-se despesas definidas quanto a natureza, estando apenas $1,28 \%$ classificadas como diversas.

Por não haver um fluxo histórico de registros econômico-financeiros, a comparabilidade foi feita entre os candidatos por haver a padronização da contabilidade feita pelos candidatos e seus comitês, evidenciando que os candidatos que mais arrecadaram e gastaram foram aqueles que conquistaram mais votos. Demonstrou-se, também, que aqueles que lideraram os gastos mais representativos estavam entre os cinco maiores arrecadadores durante o pleito de 2014.

A falta de tempestividade foi encontrada em $51 \%$ das prestações finais entregues, estando os oito candidatos eleitos dentro desse percentual final. Com isso, fica nítido que as prestações não são entregues em tempo hábil, a contar do prazo legal que estipula sua entrega em até 30 dias após as eleições, estando assim sua divulgação obrigatória sendo feita após o exercício do voto pela população. Para preencher essa lacuna, o TSE criou a figura da prestação de contas intermediária (parcial), que deveria ser feita durante o período de campanha, porém $50 \%$ das prestações na primeira parcial e $8 \%$ na segunda parcial foram entregues após o período legal.

Diante do exposto, portanto, as prestações de contas analisadas não estão em sua totalidade cobertas pelas características qualitativas da informação contábil, devido ao alto índice de despesas comprometidas pela falta de informação que são impactantes na tomada de decisão dos usuários. Prejudicada também pela dificuldade de análise das receitas de natureza estimáveis em recursos financeiros, por não especificar do que se trata para maior entendimento e pela não tempestividade da divulgação das prestações de contas. Portanto, as informações contábeis 
demonstradas nas prestações de contas não são uma base segura para o julgamento das contas, tornando-as pouco transparentes.

Pesquisas que busquem contribuir para o aperfeiçoamento e qualidade das informações contidas em prestações de contas eleitorais podem ser feitas com base no estudo das prestações de diferentes candidatos a outros cargos eletivos, assim como análises das principais ressalvas presentes nas prestações e a observação detalhada dos custos das campanhas eleitorais.

\section{REFERÊNCIAS}

ABRUCIO, Fernando L.; LOUREIRO, Maria R. Finanças públicas, democracia e accountability: debate teórico e o caso brasileiro. Economia do setor público no Brasil. Rio de Janeiro: Elsevier; Campus, 2004. p. 75-102.

Brasil(1988). Constituição (1988).Constituição da República Federativa do Brasil. Brasília, DF: Senado.

. Lei $\mathrm{n}^{\circ}$ 9.504, de 30 de setembro de 1997. Dispõe sobre o estabelecimento de normas para as eleições. Presidência da República, Casa Civil, Subchefia para Assuntos Jurídicos. Disponível em <http://www.planalto.gov.br/ccivil_03/leis/19504.htm> acessado em 05/01/2015.

. Decreto-Lei 9.295/46. Cria o Conselho Federal de Contabilidade, define as atribuições do Contador e do Guarda-livros, e dá outras providências. Disponível em http://presrepublica.jusbrasil.com.br/legislacao/126558/decreto-lei-9295-46 acessado em $11 / 05 / 2015$.

. Lei $\mathrm{n}^{\circ}$ 4.737, de 15 de julho de 1965. Institui o Código Eleitoral. Presidência da República. Disponível em: http://www.planalto.gov.br/ccivil_03/leis/14737.htm>. Acesso em: 15/01/2015.

Lei $\mathrm{n}^{\circ}$ 9.096, de 19 de setembro de 1995. Dispõe sobre partidos políticos, regulamenta os arts. 17 e 14, §3º, inciso V, da Constituição Federal. Presidência da República, Casa Civil, Subchefia para Assuntos Jurídicos. Disponível http://www.planalto.gov.br/ccivil_03/leis/19096.htm acessado em 11/05/2015.

CAMPOS, Anna Maria. Accountability: quando poderemos traduzi-la para o português? Revista de Administração Pública, Rio de Janeiro, fev./abr. 1990.

CARVAlHO, Fabiane Machado de; COLARES, Ana Carolina Vasconcelos. Percepção dos profissionais contábeis sobre as características qualitativas de melhoria da informação contábil-financeira. $5^{\circ}$ Congresso UFSC de Controladoria e Finanças; $5^{\circ}$ Congresso UFSC de Iniciação Científica em Contabilidade. Florianópolis - SC, 2014.

CASTRO, Domingos Poubel de. Auditoria, Contabilidade e Controle interno no Setor Público: integração das áreas do ciclo de gestão: planejamento, orçamento, finanças, contabilidade e auditoria e organização dos controles internos, como suporte à governança corporativa. 5.ed. São Paulo: Atlas, 2013.

CFC, Conselho Federal de Contabilidade. Resolução CFC no 1374/2011. Dá nova redação à NBC TG ESTRUTURA CONCEITUAL - Estrutura Conceitual para Elaboração e Divulgação de Relatório Contábil-Financeiro.

CVM, Comissão de Valores Mobiliários. Deliberação CVM 539/2008. Aprova o Pronunciamento Conceitual Básico do CPC que dispõe sobre a Estrutura Conceitual para a Elaboração e Apresentação das Demonstrações Contábeis. Disponível em http://www.cvm.gov.br/export/sites/cvm/legislacao/anexos/deli/0500/deli539.pdf acessado em 11/05/2015. 
LIMA, Diana Vaz de. Contabilidade pública: integrando União, Estados e Municípios (SIAFI e SIAFEM. 3. Ed. 4. Reimpr. São Paulo: Atlas, 2011.

MATTOS, José João Appel. Partidas dobradas: eleições 2014: contabilidade necessária. Ed. Atualizada. 3.ed. Brasilia: CFC:OAB, 2014.

MORAIS, Carlos Mesquita. Escalas de Medida, Estatística Descritiva e Inferência Estatística. Apostila - Escola Superior de Educação: Instituto Politécnico de Bragança. Bragança - Portugal, 2005.

NICOLAU, Jaime Marconi. Eleições no Brasil: Do Império aos dias atuais. Rio de Janeiro: Zahar, 2012.

NIYAMA, Jorge Katsumi. SILVA, Cesar Augusto Tibúrcio. Teoria da Contabilidade. 2.ed. São Paulo: Atlas, 2011.

Platt Neto, O. A.et al. (2007) Publicidade e Transparência das Contas Públicas: obrigatoriedade e abrangência desses princípios na administração pública. Contabilidade Vista e Revista, 18(1), pp. $75-94$.

PINHO, José A. G.; SACRAMENTO, Ana R. S. Accountability: já podemos traduzi-la para o português? Revista de Administração Pública, Rio de Janeiro, v. 43, n. 6, p. 1343-1368, nov./dez. 2009.

REZENDE, Ricardo Borges de. Processo de Prestação de Contas e Controle Social por meio da Pesquisa Participante: Uma análise do Conselho Municipal de Saúde do Município de Anápolis-GO. Dissertação (mestrado) - Universidade de Brasília. Faculdade de Economia, Administração e Ciências Contábeis e Atuariais - FACE. Programa Multi-institucional e InterRegional de Pós-Graduação em Ciências Contábeis (UnB/UFPB/UFRN). Brasilia - DF: O autor, 2013.

ROCHA, A. C. Accountability na Administração Pública: modelos teóricos e abordagens. Contabilidade, Gestão e Governança - Brasília/DF. v. 14. n. 2. p. 82-97. mai/ago, 2011.

SANCHEZ, Alfredo Chirino. Direito de Acesso a Informações públicas e ao escrutínio público: a transparência como instrumento de controle democrático. OCDE (2002). Transparência e Responsabilização no Setor Público. Coleção Gestão Pública, Brasília.

SILVA, Alexandre César Batista da. Uma análise de prestações de contas de candidatos majoritários no pleito de 2004 nos municípios da região metropolitana do Recife a luz das características qualitativas da informação contábil. Dissertação (mestrado) - Universidade Federa de Pernambuco. Recife: O autor, 2007.

TSE, Tribunal Superior Eleitoral. Resolução TSE $\mathbf{n}^{\circ}$ 23.406/2014. Dispões sobre arrecadação e aplicação de recursos nas campanhas eleitorais e sobre a prestação de contas nas eleições de 2014. Tribunal Superior Eleitoral. Disponível em <http://www.tse.jus.br/eleicoes/eleicoes2014/normas-e-documentacoes/resolucao-no-23.406 > acessado em 05/01/2015. 